\title{
Analysis of Climate Change in the Coastal Zone of Eastern China, against the Background of Global Climate Change over the Last Fifty Years: Case Study of Shandong Peninsula, China
}

\author{
Qing Tian', Qing Wang ${ }^{1}$, Chao Zhan ${ }^{1}$, Xiguo Li $^{2}$, Xueping Liu ${ }^{3}$ \\ ${ }^{1}$ Coast Institute, Ludong University, Yantai, China \\ ${ }^{2}$ Hydrology and Water Resources Survey Bureau, Yantai, China \\ ${ }^{3}$ Yantai Meteorological Bureau, Yantai, China \\ Email: tianqing0405@163.com
}

Received December 20, 2011; revised February 16, 2012; accepted March 15, 2012

\begin{abstract}
The climate change in Shandong Peninsula, China was analyzed in this paper by the non-parametric Mann-Kendall test, Accumulated Difference Curve and Order Cluster Analysis methods, based upon the datas of annual mean, maximum and minimum temperature and annual precipitation, precipitation from June to September over the past 50 years. Results obtained showed a number of observations: 1) The annual mean temperature of Shandong Peninsula showed a significant increasing trend, with a distinct abrupt change point detected around 1990, during the past 5 decades. The warming of the Peninsula over the last 50 years was due mainly to the significant increase of annual minimum temperature. The annual maximum temperature demonstrated a mixed trend of decreasing and increasing, but was statistically insignificant, and no abrupt change was detected; 2) The annual precipitation exhibited a decreasing trend during the past 5 decades, with an abrupt change detected around 1980 at most stations; but there was an earlier transition point at 1966, at a few stations. The reduction in precipitation, from June to September, was responsible mainly for the decrease of annual precipitation. Besides, the proportion of the June-September precipitation in the year declined slightly over the last 50 years; 3 ) In comparison, the temperature evolution in Shandong Peninsula was basically consistent with most parts of China, but warmed at a faster rate over the same period; the decreasing trend of precipitation was more significant compared with the other climate zones of China. Within the Peninsula, the abrupt change of temperature and precipitation in the Southeast was earlier than that in the Northwest; the reduction of precipitation was larger in the Southeast while the increase of temperature was more significant in the Northwest. This research was of great importance to understand the climate change and its environmental effects in the coastal zone.
\end{abstract}

Keywords: Abrupt Change; Climate Change; Shandong Peninsula in China; The Last Fifty Years; Coastal Zone

\section{Introduction}

Climate is an integral part of natural environment that humans depend upon for survival; global climate change has become a hot issue, and attracted the common concern of governments and scientists. Global climate change, especially global warming has been a scientific fact that not can be avoided during the past 100 years [1-7]. The global average surface temperature has increased $0.74^{\circ} \mathrm{C}$ during the 20th Century (1906-2005) according to IPCC (2007). The coastal zone is the narrow strip located between land and sea. As the most developed region which is densely populated, the climate change in the coastal zone has a special significance to the development of human society $[8,9]$. Additionally, the coastal zone in- volved in this article represents the interface between land, sea and the atmosphere, and there exists frequent exchange of moisture, heat fluxes, sediment, and important nutrient elements like C, N, S between land and sea; also, the coastal wetland ecosystem affects the concentration of greenhouse gases in the atmosphere, like $\mathrm{CH}_{4}$, $\mathrm{CO}_{2}$ and water vapor [10]. Thus, the climate change in the coastal zone will have a profound impact on global climate change. However, climate change in the coastal zone is not only affected by global climate change, also, it has its particular patterns inevitably, as the coastal climate suffers the combined effect of atmosphere circulation from the continent and the ocean, and there exists two underlying surfaces of ocean and land which have totally different thermal properties in the coastal zone 
[11]. Therefore, climate change in the coastal zone deserves further research.

China is situated in the Eastern Eurasia, which borders on the west coast of the Pacific Ocean, with a coastline of more than $18,000 \mathrm{~km}$. The east coast of China comprises an area of 3 million $\mathrm{km}^{2}$, and stretches across the tropical, subtropical and temperate zone, from south to north [12]. More than $41 \%$ of the national population, $50 \%$ of the large and medium-sized cities are located in the coastal zone of China, and it account for more than $60 \%$ of the gross domestic productivity (GDP) [13], so the coastal development in China plays a leading role in the national economy. Affected by the different thermal properties of the largest continent and ocean, the east coast of China is dominated by a typical East Asian monsoon climate $[14,15]$. In this paper, climate change in the eastern coastal zone during the last 50 years was analyzed taking Shandong Peninsula, which is located in the temperate zone of Eastern China, as an example, to further reveal the temperate monsoon climate evolution under global climate change. Therefore, this research is not only of great importance to understand climate change and its environmental effects in the coastal zone, but also has important practical value for us to cope with global change, to achieve regional sustainable development, and to implement the planning of the blue economic zone in Shandong Peninsula particularly.

\section{Study Area}

Located on the east of Jiaolai River, which connected Laizhou Bay and Jiaozhou Bay, and extended eastward between the Bohai Sea and the Yellow Sea, Shandong Peninsula is the largest Peninsula in China $\left(35^{\circ} 35^{\prime}\right.$ $38^{\circ} 23^{\prime} \mathrm{N}, 119^{\circ} 30^{\prime}-122^{\circ} 42^{\prime} \mathrm{E}$ ), with an area of $2.7 \times 10^{4}$ $\mathrm{km}^{2}$ (Figure 1). The main landform of the Peninsula was dominated by old metamorphic, granitic hills, and only a few medium and low mountains protrude above the hills with gently rolling topography. Mountainous area accounted for about $70 \%$ of the total area, with an elevation of about 200 meters. The mountains in the Peninsula, mainly includes Ya, Kunyu, Weide, Luo et al., was a nearly eastwest strike and was close to the Northern Peninsula. They were about 500 - 1000 meters above the sea level, in which, Laoshan Mountain was the highest $(1130 \mathrm{~m})$. Shandong Peninsula has developed a typical temperate bedrock coast with a winding coastline [14].

Shandong Peninsula was under the control of SiberianMongolian high-pressure air masses from high latitude of the Eurasian continent in winter, with low air temperature and humidity, thus dry and cold winter monsoon from near north was formed; air masses from low latitude of the Pacific Ocean, with high temperature and humidity prevailed in summer, warm and wet summer monsoon from near south was formed consequently. Under the
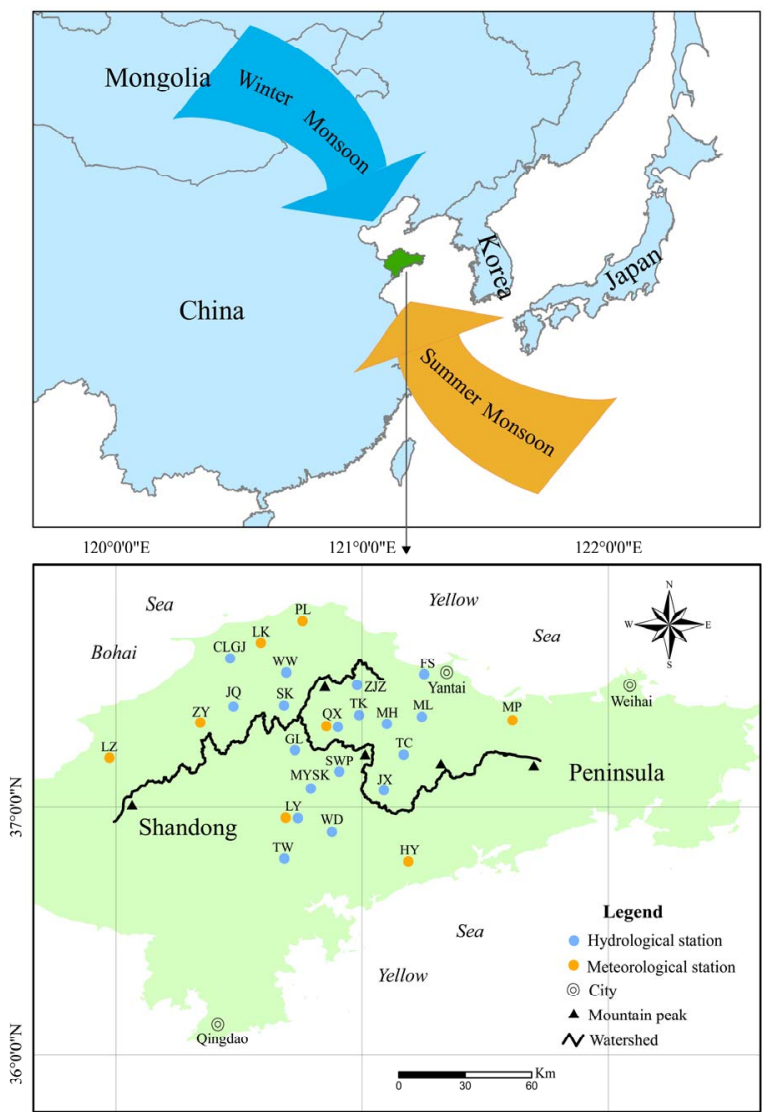

Figure 1. Location of Shandong Peninsula showing meteorological and hydrological stations and background topography. The stations are abbreviated as: HY (Haiyang); LZ (Laizhou); ZY (Zhaoyuan); JQ (Jiuqu); LK (Longkou); PL (Penglai); LY (Laiyang); MH (Miaohou); MP (Muping); CLGJ (Celinggaojia); ZJZ (Zangjiazhuang); WW (Wangwu); SK (Sikou); GL (Guanli);TK (Tiekou); MYSK (Muyushuiku); ML (Menlou); TC (Taocun); WD (Wandi); SWP (Shewopo); JX (Jianxin); FS (Fushan); QX (Qixia) and TW (Tuanwang).

control of summer monsoon and winter monsoon, Shandong Peninsula has developed a typical humid monsoon climate of warm temperate zone, the four seasons are distinct, with hot, rainy summer and cold, dry winter. Affected significantly by the summer monsoon, the annual precipitation occurs mostly in the summer season, from June to September, with strong intensity, and is often accompanied with heavy rains. The annual precipitation in Shandong Peninsula averages $600-850 \mathrm{~mm}$; the average temperature was $-3^{\circ} \mathrm{C} \sim-1^{\circ} \mathrm{C}$ in January, and about $25^{\circ} \mathrm{C}$ in August (the hottest month), the extreme maximum temperature was about $38^{\circ} \mathrm{C}$, and thus the annual temperature range was large [14].

Affected by the ocean, Shandong Peninsula had an annual precipitation which is $200-300 \mathrm{~mm}$ more than that of the continental interior area at the same latitude, together with cooler summer. Since Shandong Peninsula was close to the small-sized Bohai Sea on the northwest and 
bordered the vast Yellow Sea on the southeast, meanwhile the mountain ranges in the central Peninsula were a barrier to prevent the warm and moist air mass from the Yellow sea penetrating into the Peninsula, and thus the influence of the ocean to the climate weakened from southeast to northwest of the Peninsula. For instance, the annual precipitation decreased from the southeast to the northwest within Shandong Peninsula, it was above 850 $\mathrm{mm}$ in the east side, while less than $600 \mathrm{~mm}$ in the coastal plain located in the Northwestern Peninsula [16].

As the frontier area since Chinese Economic Reform, Shandong Peninsula has become one of the most developed regions in China during the last 50 years, with a large population and many cities. The major industrial companies and cities, like Qingdao, Weihai and Yantai were all located in the coastal zone (Figure 1). Since the meteorological stations set up in these cities were more likely affected by urban climate conditions, the hydrological and meteorological data from the central Peninsula were chosen here to investigate the relationship between the coastal climate of the Peninsula and global climate change.

\section{Methodology}

\subsection{Data}

It was generally acknowledged that human activities began to have a notable impact on climate since 1950's [2], and taking into account the availability of the data, the last 50 years was selected as the study period.

In this paper, the observation data of temperature and precipitation from hydrological and meteorological stations in the central Peninsula were used to analyze the climate change in Shandong Peninsula for the last 50 years. In which, the precipitation data employed were from 18 hydrological stations, including two indicators of the annual precipitation and precipitation from June to September, and the observation period was from 49 to 58 years (52 years in average); the temperature data including 3 indicators, the annual mean, maximum and minimum temperature respectively, were from 8 meteorological stations. The observation period was from 44 to 58 years (53 years in average). All of the stations mentioned above are the National Basic Weather Stations, and the observation data are continuous data records for the period of the last 50 years, of good quality. As the temperate monsoon climate in the Peninsula is characterized by the synchronization of high temperature and ample precipitation, the 5 climate indicators selected in this paper were the best to reflect its climatic characteristics. The location of the stations was shown in Figure 1.

\subsection{Methods}

In this study, the non-parametric Mann-Kendall test [17-
20], Accumulated Difference Curve [18] and Order Cluster Analysis (OCA) [21] were applied, to identify the long-term trend and the abrupt change of both precipitation and temperature series in Shandong Peninsula during the last 50 years. The Mann-Kendall test was first used to describe the general change trend for the climatic indicators. An Accumulated Difference Curve method was employed next to analyze the periodical fluctuation of the climate element series. Finally, the transition point of the series was detected by OCA, a method to find the optimal dividing point of the time-series. All of the tests were under the $95 \%$ confidence level in this paper, and were calculated by Matlab software.

\subsubsection{Mann-Kendall Test}

Mann-Kendall test is a non-parametric method, it has the advantage of not assuming any distribution form for the data series, the test capacity is not affected by the breakpoint, and is more powerful than its parametric competitors. Therefore, it is highly recommended by the World Meteorological Organization to assess the monotonic trend in hydro-meteorological time-series. This test is based on the null hypothesis Ho, which supposes that the analyzed series are independent and randomly ordered, and there is no obvious change trend. The test statistics: $Z c$ and $\beta$ are stated simply as follows.

1) Parameter $Z c$ reflects the general change trend of the series. For the analyzed series $\left(x_{1}, x_{2} \cdots x_{n}\right)$

$$
Z c=\left\{\begin{array}{lc}
\frac{S-1}{\sqrt{\operatorname{var}(S)}} & S>0 \\
0 & S<0 \\
\frac{S+1}{\sqrt{\operatorname{var}(S)}} &
\end{array}\right.
$$

In which,

$$
\begin{gathered}
S=\sum_{i=1}^{n-1} \sum_{j=i+1}^{n} \operatorname{sign}\left(x_{j}-x_{i}\right) \\
\operatorname{sign}\left(x_{j}-x_{i}\right)= \begin{cases}1 & x_{j}-x_{i}>0 \\
0 & x_{j}-x_{i}=0 \\
-1 & x_{j}-x_{i}<0\end{cases} \\
\operatorname{var}[S]=\frac{n(n-1)(2 n+5)}{18}
\end{gathered}
$$

$Z c$ follows the standard normal distribution. Therefore, $H_{o}$ is rejected if $|Z c| \leq Z_{1-\alpha / 2}$, which means there is a significant change trend for the series (abbreviated as $R$ ), while accepting $H_{o}$ suggests no obvious trend for the series (abbreviated as $A$ ). Besides, $Z c>0$ represents an upward trend of the series, while $Z c<0$ denotes a negative trend. In which, $\alpha$ is the significance level for the test; $\pm Z_{1-\alpha / 2}$ are the standard normal deviates. In this paper, $\alpha$ 
$=95 \%$ was applied, $\pm Z_{1-\alpha / 2}= \pm 1.96$.

2) Parameter $\beta$ is the Kendall gradient, and it is used to estimate of average change rate of the series. It is based on the assumption that the change trend of the series is monotonic, which means the trend is a linear function of time.

$$
\beta=\operatorname{Median}\left(\frac{x_{i}-x_{j}}{i-j}\right) \quad(1<j<i<n)
$$

\subsubsection{Accumulated Difference Curve}

For the series $\left(x_{1}, x_{2} \ldots x_{n}\right)$, the accumulated difference of every point was given as:

$$
X_{t}=\sum_{i=1}^{t}\left(X_{i}-\bar{X}\right) \quad(t=1,2, \cdots, n)
$$

In which,

$$
\bar{X}=\frac{1}{n} \sum_{i=1}^{n} X_{i}
$$

Draw the accumulated difference curve according to the results, the horizontal axis of the curve represents time (year), and the vertical axis of the curve is $\sum\left(x_{i}-\bar{X}\right)$. An upward gradient of the curve indicates a relatively high temperature period or a pluvial period; a relatively cold or dry period conversely. And thus the change process of the series can be divided into stages with different change trend, and the variation of the trend may be attributed to the abrupt change of the climatic elements.

\subsubsection{Order Cluster Analysis (OCA)}

The transition point was detected by OCA, a method to find the optimal dividing point of the time-series. This method was similar to the cluster analysis, but the sequence of the series should not be disrupted. For the series $\left(x_{1} \cdots x_{i} \cdots x_{j} \cdots x_{n}\right)(1<i<j<\mathrm{n})$, if the series with $n$ points was divided into $\mathrm{m}$ groups, the optimal dividing point was obtained as follows:

$$
\begin{gathered}
\left\{i_{1}, i_{1}+1=2, \cdots, i_{2}-1\right\} \quad\left\{i_{2}, i_{2}+1, \cdots, i_{3}-1\right\} \\
\left\{i_{k}, i_{k}+1, \cdots, i_{k+1}-1\right\} \quad\left\{i_{m}, i_{m}+1, \cdots, n\right\} \\
D(i, j)=\sum_{k=i}^{j}\left(x_{k}-\overline{x_{i j}}\right)^{\prime}\left(x_{k}-\overline{x_{i j}}\right) \\
\overline{x_{i j}}=\frac{1}{j-i+1} \sum_{k=i}^{j} x_{k} \\
\varphi\{p(m, n)\}=\sum_{k=1}^{m} D\left(i_{k}, i_{k+1}-1\right)
\end{gathered}
$$

where $k$ represents the group number, $i_{k}$ is the first sample of group $k$. The series was divided into 2 groups in this paper, and thus the point with the minimum $\varphi\{p(2$, n)\} value will be the optimal dividing point.

\section{Results}

\subsection{Change Trend of Temperature in Shandong Peninsula over the Past 50 Years}

\subsubsection{Annual Mean Temperature}

The annual mean temperature of Shandong Peninsula over the past 5 decades exhibited a significant increasing trend overall. The Mann-Kendall results showed that Ho was rejected (Table 1), which means the increasing trend of annual mean temperature series was significant at the $95 \%$ significance level. The annual mean temperature of Shandong Peninsula has increased $1^{\circ} \mathrm{C}-2^{\circ} \mathrm{C}$ approximately over the past 5 decades, with an average increasing rate of $0.26^{\circ} \mathrm{C}-0.46^{\circ} \mathrm{C}(10 \mathrm{a})^{-1}$ (Table 1).

The long-term trend of annual mean temperature in Shandong Peninsula was characterized by distinct periodical fluctuations over the past 50 years, instead of monotonic increasing trend. The accumulated difference curves showed that 1990 can be defined as the split point, to divide the annual mean temperature series into two periods: a downward trend in the early period and a continuous increasing trend in the late period (Figure 2(a)). As a consequence, there may be an abrupt change of annual mean temperature around 1990: it shifted from a relatively cool period to a warm period after 1990 .

According to the results of OCA, the transition point of annual mean temperature at all stations existed in the period of 1988-1994, the annual mean temperature increased by $7.52 \%-12.21 \%$ after the abrupt change (Table 2). Therefore, 1990 could be considered as the dividing point on the whole, and the annual mean temperature increased by about $10 \%$ after 1990 , over the past 5 decades in Shandong Peninsula. Additionally, as can be seen from Figure 1 that the stations with more significant in creasing rate of annual mean temperature were mostly located in the northwest of the Peninsula during the past 50 years.

The temperature increase in Shandong Peninsula should be an active local response to global warming, but the specific change process and the exact transition point were not quite the same. The increasing rate of annual mean temperature for the past 50 years in Shandong Peninsula was much higher than that of the entire globe (an increasing rate of $0.13^{\circ} \mathrm{C}(10 \mathrm{a})^{-1}$ from 1906 to 2005) according to the IPCC (2007), China (an increasing rate of $0.3^{\circ} \mathrm{C}(10 \mathrm{a})^{-1}$ from 1961 to 2006$)$ [22] and the monsoon region of Eastern China (an increasing rate of $0.26^{\circ} \mathrm{C}$ $(10 \mathrm{a})^{-1}$ from 1951 to 2002) [23], also, it was more significant compared to the western inland area, at the same latitude (an increasing rate of $0.18^{\circ} \mathrm{C}(10 \mathrm{a})^{-1}$ from 1951 to 2002) [24]. Moreover, many research have found that the transition point of annual mean temperature was observed at 1993 in the Northern Hemisphere [25], 1989 in China [22], 1992 in the warm temperate zone where 
Table 1. Monotonic trend tests for the annual mean/maximum/minimum temperature time-series in Shandong Peninsula.

\begin{tabular}{|c|c|c|c|c|c|c|c|c|c|}
\hline \multirow{2}{*}{ Station } & \multirow{2}{*}{ Period } & \multicolumn{2}{|c|}{ Annual mean temperature } & \multicolumn{3}{|c|}{ Annual minimum temperature } & \multicolumn{3}{|c|}{ Annual maximum temperature } \\
\hline & & $Z c$ & $\beta$ & $Z c$ & $\beta$ & $H_{o}$ & $Z c$ & $\beta$ & $H_{o}$ \\
\hline HY & $1959-2009$ & 5.13 & 0.033 & 3.74 & 0.069 & $\mathrm{R}$ & -0.19 & -0.003 & A \\
\hline $\mathrm{LZ}$ & $1959-2009$ & 5.16 & 0.035 & 3.38 & 0.067 & $\mathrm{R}$ & -0.42 & -0.006 & A \\
\hline ZY & $1957-2009$ & 5.31 & 0.03 & 4.87 & 0.109 & $\mathrm{R}$ & -1.50 & -0.022 & A \\
\hline LK & $1957-2009$ & 6.38 & 0.046 & 5.14 & 0.14 & $\mathrm{R}$ & 0.72 & 0.01 & $\mathrm{~A}$ \\
\hline PL & 1959-2009 & 4.49 & 0.029 & 2.57 & 0.05 & $\mathrm{R}$ & -1.08 & -0.021 & A \\
\hline LY & 1952-2009 & 5.98 & 0.033 & 3.49 & 0.052 & $\mathrm{R}$ & 0.72 & 0.008 & $\mathrm{~A}$ \\
\hline QX & $1959-2009$ & 4.76 & 0.026 & 3.05 & 0.06 & $\mathrm{R}$ & 0.11 & 0 & A \\
\hline MP & $1961-2009$ & 5.57 & 0.041 & 2.09 & 0.052 & $\mathrm{R}$ & 1.15 & 0.024 & A \\
\hline
\end{tabular}

Table 2. Transition point of the annual mean/maximum/minimum temperature time-series at 8 meteorological stations in Shandong Peninsula.

\begin{tabular}{|c|c|c|c|c|c|}
\hline \multirow{2}{*}{ Station } & \multirow{2}{*}{ Period } & \multicolumn{2}{|c|}{ Annual mean temperature } & \multicolumn{2}{|c|}{ Annual minimum temperature } \\
\hline & & Transition Point & Increase & Transition Point & Increase \\
\hline HY & $1959-2009$ & 1988 & $8.52 \%$ & 1972 & $18.70 \%$ \\
\hline $\mathrm{LZ}$ & 1959-2009 & 1994 & $9.23 \%$ & 1986 & $20.12 \%$ \\
\hline ZY & $1957-2009$ & 1994 & $9.72 \%$ & 1986 & $22.45 \%$ \\
\hline LK & $1957-2009$ & 1989 & $12.21 \%$ & 1994 & $34.18 \%$ \\
\hline PL & $1959-2009$ & 1988 & $7.52 \%$ & 1986 & $17.36 \%$ \\
\hline LY & $1952-2009$ & 1994 & $11.16 \%$ & 1987 & $16.50 \%$ \\
\hline QX & 1959-2009 & 1989 & $7.66 \%$ & 1992 & $17.32 \%$ \\
\hline MP & 1961-2009 & 1994 & $11.19 \%$ & 1987 & $16.83 \%$ \\
\hline
\end{tabular}
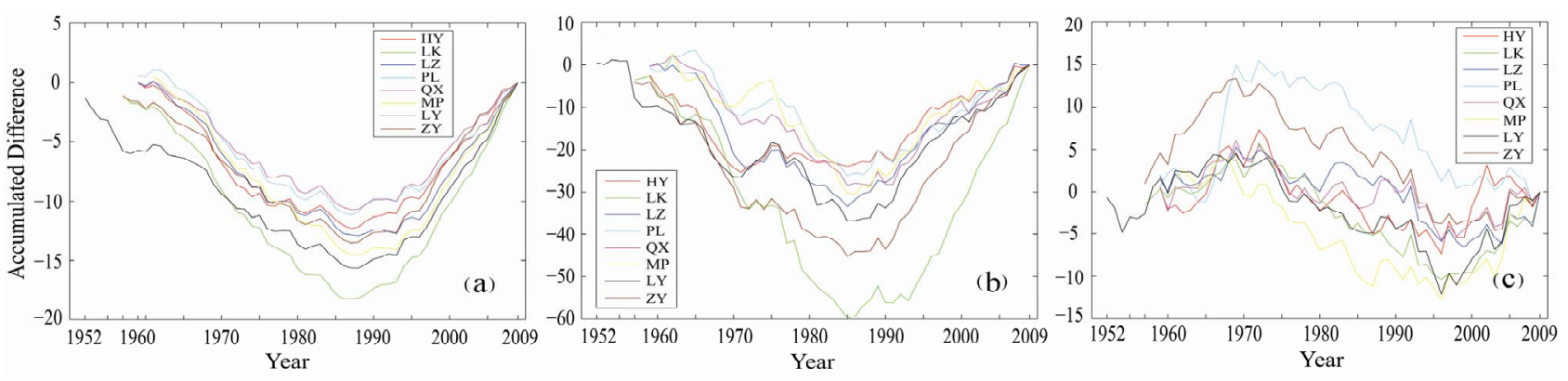

Figure 2. Accumulated difference curve of the annual mean (a) minimum (b) and maximum (c) temperature at 8 meteorological stations in Shandong Peninsula.

Shandong Peninsula located [22], and 1990 in the western inland area at the same latitude [22]. Apparently, the late 1980 s or the early 1990 s in the 20th century was an important period for temperature mutation in the Northern Hemisphere. The abrupt change of annual mean temperature detected in Shandong Peninsula was mostly concentrated in this period too.

\subsubsection{Annual Minimum Temperature}

The annual minimum temperature has increased significantly during the last 50 years in Shandong Peninsula. The Mann-Kendall results of annual minimum tempera- ture rejected $H_{o}$, meaning that the increasing trend of annual minimum temperature achieved the 95\% significance level (Table 1). And the annual minimum temperature was observed an increase of $2^{\circ} \mathrm{C}-7^{\circ} \mathrm{C}$ approximately over the past 5 decades, with an average increasing rate of $0.5^{\circ} \mathrm{C}-1.4^{\circ} \mathrm{C}(10 \mathrm{a})^{-1}$ in Shandong Peninsula (Table 1). This observation was in agreement with the conclusions that the annual minimum temperature showed a significant increasing trend over the past 50 years in China [7,26-28], the north of $35^{\circ} \mathrm{N}$ especially [24].

The rising process of annual minimum temperature in Shandong Peninsula showed distinct periodical fluctua- 
tions over the past 5 decades, but not a monotonic increasing trend. The accumulated difference curves at most stations showed a decreasing trend before 1990, a continuous increasing trend afterwards, but there was an obvious fluctuation around 1970 (Figure 2(b)). Since it can be inferred that the possible transition point of annual minimum temperature existed around 1990. However, accumulated difference curve for Haiyang station appeared to show a decreasing trend before 1970s, an increasing trend after 1990 and a horizontal period between them (Figure 2(b)). Evidently, the abrupt change of annual minimum temperature probably existed in 1970s1990s at Haiyang station.

The OCA results showed that the transition point of annual minimum temperature at most stations was in the period of 1986-1994, except Haiyang Station, which has an earlier transition point at 1972 (Table 2). Moreover, the annual minimum temperature showed an increase of $16.50 \%$ - 34.18\% after the abrupt change (Table 2). Therefore, the annual minimum temperature in Shandong Peninsula increased by about $20 \%$ after 1990 over the past 5 decades, and thus the abrupt change was distinct.

\subsubsection{Annual Maximun Temperature}

The annual maximum temperature demonstrated a mixed trend of decreasing and increasing over the past 50 years in Shandong Peninsula. Longkou, Muping, Laiyang and Qixia stations showed a slight upward trend of annual maximum temperature, while it displayed a gentle decreasing trend at Haiyang, Laizhou, Penglai and Zhaoyuan station. The Mann-Kendall test indicated that the change trend was statistically insignificant (Table 1). Furthermore, the change pattern of annual maximum temperature was quite complex and no obvious abrupt change was observed, seen from the accumulated differrence curve (Figure 2(c)).

According to the analysis described above, the increase amplitude in annual minimum temperature was much higher than that of the annual maximum temperature in Shandong Peninsula over the last 50 years. Consequently, the climate warming of Shandong Peninsula over the last 50 years was largely due to the significant increase of annual minimum temperature, especially after the 1990s. A similar story exists all over China [29].

\subsection{Precipitation Changes in Shandong Peninsula over the Past 50 Years}

\subsubsection{Annual Precipitation}

The annual precipitation of Shandong Peninsula exhibited a decreasing trend during the last 50 years. The Mann-Kendall test results indicated that the annual precipitation at 18 stations showed a decreasing trend, and the decreasing trend was significant at Muyushuiku, Laiyang, Tiekou, Miaohou and Menlou stations (Table 3).
The annual precipitation was observed a decrease of about 60 - $200 \mathrm{~mm}$ over the past 5 decades, the decreasing rate was $1.33-4.13 \mathrm{~mm} \cdot \mathrm{a}^{-1}$, with an average value of $2.73 \mathrm{~mm} \cdot \mathrm{a}^{-1}$ (Table 3). Thus, the annual precipitation reduction differs considerably in different regions of Shandong Peninsula. The decreasing rate of annual precipitation over the past 50 years in Shandong Peninsula is slightly higher than that of the warm temperate zone in China $\left(-2.13 \mathrm{~mm} \cdot \mathrm{a}^{-1}\right)$, which was detected a more marked reduction in annual precipitation than the other climate zones of China [22,26]. Therefore, the decreasing trend of annual precipitation in Shandong Peninsula over the past 50 years was more notable compared with the other climate zones of China.

The change process of annual precipitation in Shandong Peninsula showed obvious periodical fluctuations, other than monotonic increasing trend over the past 5 decades. The accumulated difference curves at Muyushuiku, Laiyang and Shewopo stations showed an increasing trend before 1966, after a short-term fluctuation, then started to decrease around 1980 (Figure 3(a)). However, the accumulated difference curves for the other 15 stations were divided into 2 periods at 1980, but there was an obvious fluctuation at about 1966, especially the Sikou, Tuanwang, Zangjiazhuang and Wandi station (Figure 3(b)). This suggested that the annual precipitation transitioned from a relatively wet season to a dry season after 1980s in the study area. Therefore, 1966 or 1980 was thought as the possible transition point of annual precipitation in Shandong Peninsula. Further analysis based to the results of OCA showed that, the transition point of annual precipitation was 1966 at Muyushuiku, Laiyang and Shewopo station, which were located in the Southeastern Peninsula, while that at the other 15 stations was around 1980 (Table 4), this is the same time when the major precipitation belt moved in a Northern to Southern China trajectory throughout the last 50 years [30].

The annual precipitation in Shandong Peninsula has decreased after the abrupt change with the reduction magnitude ranges from $13.81 \%$ to $24.75 \%$ over the past 5 decades, and the mean value was $18.77 \%$ approximately (Table 4). The study area can be divided into two parts: the northwest (9 stations) and the southeast (9 stations), respectively, according to the line joining points of Yantai and Miaohou. Among the 8 stations with the reduced amplitude of annual precipitation below the mean value (18.77\%), 7 were located in the northwest, while only 2 of the 10 stations with the reduced amplitude above the mean value (18.77\%) were located in the northwest (Figure 1). Therefore, the reduction of annual precipitation in the northwest was much smaller than that in the southeast in the past 50 years.

Different from the decreasing trend of annual precipi- 
Table 1. Monotonic trend tests for the annual/June-September precipitation time-series at 18 hydrological stations in Shandong Peninsula.

\begin{tabular}{|c|c|c|c|c|c|c|c|c|}
\hline \multirow{2}{*}{ Station } & \multicolumn{4}{|c|}{ Annual precipitation } & \multicolumn{4}{|c|}{ June-September precipitation } \\
\hline & Period & $Z c$ & $\beta$ & $H_{o}$ & Period & $Z c$ & $\beta$ & $H_{o}$ \\
\hline JQ & $1965-2009$ & -1.13 & -2.34 & A & $1965-2009$ & -1.54 & -2.31 & A \\
\hline CLGJ & $1960-2009$ & -1.2 & -2.24 & A & $1960-2009$ & -1.16 & -2.22 & A \\
\hline WW & $1959-2009$ & -0.96 & -1.33 & A & $1959-2009$ & -1.24 & -1.84 & A \\
\hline SK & $1956-2009$ & -1.36 & -2.13 & A & $1958-2009$ & -1.35 & -2.41 & A \\
\hline GL & $1952-2009$ & -1.05 & -1.49 & A & $1952-2009$ & -1.25 & -2.07 & $\mathrm{~A}$ \\
\hline MYSK & $1956-2009$ & -2.16 & -3.42 & $\mathrm{R}$ & $1959-2009$ & -1.97 & -3.13 & $\mathrm{R}$ \\
\hline LY & $1956-2009$ & -2.2 & -3.24 & $\mathrm{R}$ & $1956-2009$ & -1.84 & -2.95 & $\mathrm{~A}$ \\
\hline TW & $1952-2009$ & -1.8 & -2.4 & A & $1957-2009$ & -1.07 & -1.84 & A \\
\hline WD & $1952-2009$ & -1.83 & -2.57 & A & $1952-2009$ & -1.47 & -1.88 & A \\
\hline SWP & $1953-2009$ & -1.8 & -2.79 & A & $1953-2009$ & -1.69 & -2.79 & A \\
\hline JX & $1956-2009$ & -1.69 & -3.04 & A & $1960-2009$ & -1.99 & -3.47 & $\mathrm{R}$ \\
\hline TK & $1952-2009$ & -2.07 & -3.25 & $\mathrm{R}$ & $1952-2009$ & -2.12 & -2.98 & $\mathrm{R}$ \\
\hline MH & $1960-2009$ & -2.08 & -3.95 & $\mathrm{R}$ & $1960-2009$ & -2.12 & -3.48 & $\mathrm{R}$ \\
\hline ZJZ & $1960-2009$ & -1.36 & -2.21 & A & $1960-2009$ & -1.64 & -2.58 & A \\
\hline FS & $1966-2009$ & -1.61 & -3.68 & A & $1966-2009$ & -1.35 & -2.8 & A \\
\hline ML & $1960-2009$ & -2.41 & -4.13 & $\mathrm{R}$ & $1960-2009$ & -2.31 & -4.44 & $\mathrm{R}$ \\
\hline $\mathrm{TC}$ & $1952-2009$ & -1.36 & -1.81 & A & $1952-2009$ & -1.47 & -2.37 & A \\
\hline QX & $1960-2009$ & -1.82 & -3.09 & A & $1960-2009$ & -1.66 & -2.95 & A \\
\hline
\end{tabular}

Table 2. Transition points of the annual/June-September precipitation time-series at 18 hydrological stations in Shandong Peninsula.

\begin{tabular}{|c|c|c|c|c|c|c|}
\hline \multirow{2}{*}{ Station } & \multicolumn{3}{|c|}{ Annual precipitation } & \multicolumn{3}{|c|}{ June-September precipitation } \\
\hline & Period & Transition point & Decrease & Period & Transition point & Decrease \\
\hline JQ & $1965-2009$ & 1979 & $14.44 \%$ & $1965-2009$ & 1979 & $19.08 \%$ \\
\hline CLGJ & $1960-2009$ & 1986 & $17.27 \%$ & 1960-2009 & 1986 & $20.54 \%$ \\
\hline WW & 1959-2009 & 1979 & $15.08 \%$ & 1959-2009 & 1979 & $20.77 \%$ \\
\hline SK & $1956-2009$ & 1977 & $14.61 \%$ & $1958-2009$ & 1977 & $16.55 \%$ \\
\hline GL & $1952-2009$ & 1980 & $13.81 \%$ & $1952-2009$ & 1980 & $15.77 \%$ \\
\hline MYSK & $1956-2009$ & 1966 & $22.11 \%$ & $1959-2009$ & 1966 & $31.27 \%$ \\
\hline LY & $1956-2009$ & 1966 & $24.75 \%$ & $1956-2009$ & 1966 & $29.51 \%$ \\
\hline TW & $1952-2009$ & 1977 & $20.09 \%$ & $1957-2009$ & 1966 & $29.32 \%$ \\
\hline WD & $1952-2009$ & 1977 & $20.01 \%$ & $1952-2009$ & 1966 & $23.94 \%$ \\
\hline SWP & $1953-2009$ & 1966 & $18.84 \%$ & $1953-2009$ & 1966 & $22.85 \%$ \\
\hline JX & 1956-2009 & 1977 & $22.98 \%$ & 1960-2009 & 1977 & $26.78 \%$ \\
\hline TK & $1952-2009$ & 1980 & $23.68 \%$ & $1952-2009$ & 1980 & $26.79 \%$ \\
\hline MH & $1960-2009$ & 1977 & $19.37 \%$ & $1960-2009$ & 1979 & $21.47 \%$ \\
\hline ZJZ & 1960-2009 & 1980 & $15.93 \%$ & $1960-2009$ & 1979 & $20.11 \%$ \\
\hline FS & $1966-2009$ & 1977 & $20.26 \%$ & $1966-2009$ & 1979 & $23.05 \%$ \\
\hline ML & $1960-2009$ & 1980 & $22.13 \%$ & 1960-2009 & 1979 & $27.84 \%$ \\
\hline $\mathrm{TC}$ & $1952-2009$ & 1977 & $14.29 \%$ & $1952-2009$ & 1979 & $16.74 \%$ \\
\hline QX & $1960-2009$ & 1980 & $18.16 \%$ & $1960-2009$ & 1980 & $21.63 \%$ \\
\hline
\end{tabular}



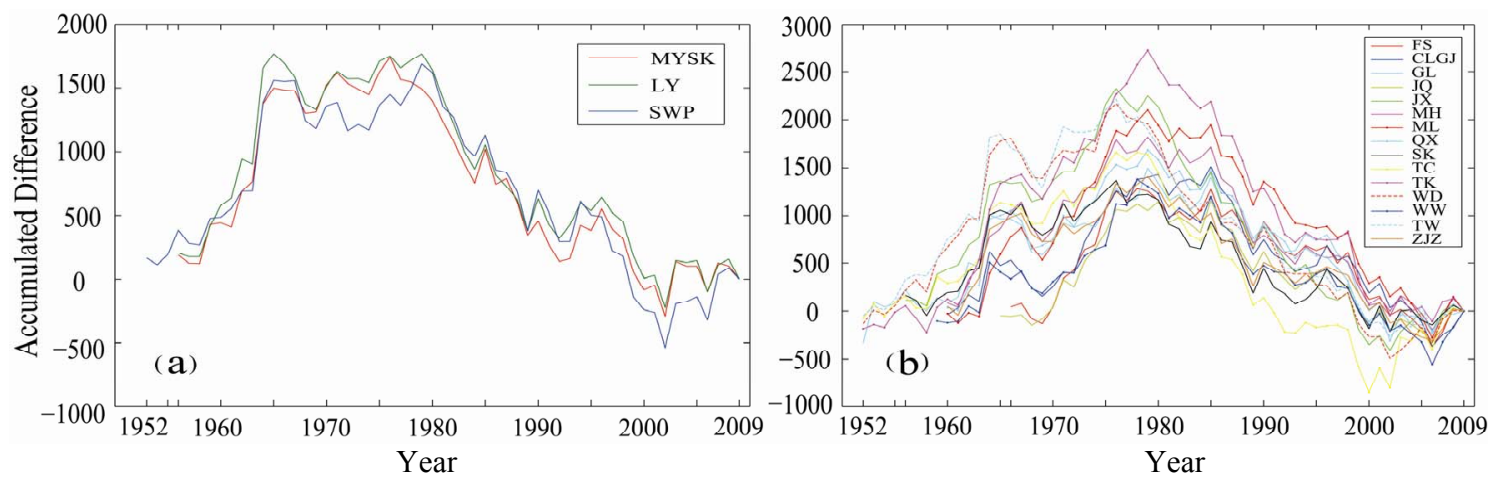

Figure 3. Accumulated difference curve of the annual precipitation at 18 hydrological stations in Shandong Peninsula.

tation in Shandong Peninsula, it exhibited an increasing trend in the western inland area at the same latitude over the last 50 years $[7,19,26,31]$, with the transition point concentrated in mid-1980s [22,32], which is a little later than that of the Shandong Peninsula. Consequently, Shandong Peninsula was becoming warmer and drier gradually, while the western inland area showed a transition to warmer and wet conditions during the recent 50 years.

\subsubsection{Precipitation from June to September}

Shandong Peninsula has developed a typical humid monsoon climate of warm temperate zone, with most precipitation falls mainly in summer season (from June to September). The research results show that, the average percent of precipitation from June to September of the year was $67.19 \%-74.61 \%$ in the 18 hydrological stations of Shandong Peninsula, the average value was $71.93 \%$ (Table 5). Therefore, the analysis on the evolution of summer precipitation and the proportion of precipitation from June-September of the year is of great significance to understand the monsoon climate change over the last 50 years.

The change characteristics, as well as the transition point of June-September precipitation, were basically consistent with that of the annual precipitation in Shandong Peninsula over the past 5 decades (Tables 3 and 4), but the proportion of June-September precipitation in annual precipitation decreased slightly (Table 5). It suggests the reduction of June-September precipitation was responsible mainly for the decrease of annual precipitation. The June-September precipitation reduced by $15.77 \%$ $31.27 \%$ after the abrupt change, and the mean value was about 23\% (Table 4). Within the Peninsula, the reduction magnitude of June-September precipitation at 10 stations was under the mean value (23\%), in which, 7 were located in the northwest, but only 2 out of the 8 stations with the reduction magnitude above the mean value $(23 \%)$ were located in the northwest. Therefore, the reduction magnitude in the southeast was more remarkable than that in the northwest.

\section{Discussion}

\subsection{The Relationship between Temperature and Precipitation Changes}

On a global or large regional scale, the regional water cycle process will alter with the rising temperature; also, it will affect the amount of precipitation and evaporation $[33,34]$. However, changes in precipitation and temperature showed different collocation scenarios in different regions. For example, increasing temperature was identified all over China during the past 50 years, while the annual precipitation increased in South China, but decreased in the North $[19,26,35]$, or decreased in East China, but increased in the west [7,31]. As has been argued above, the temperature has increased significantly in Shandong Peninsula with an abrupt change detected around 1990; whilst the precipitation decreased with an inflection point around 1980. Consequently, increasing temperature collocated with decreasing precipitation in Shandong Peninsula during the study period, both showed distinct periodical fluctuations and abrupt changes, but the abrupt change in precipitation was 10 years earlier than that of the temperature. In addition, the annual temperature range and the proportion of June-September precipitation in annual precipitation has decreased slightly. However, changes in temperature and precipitation over the past 50 years have not modified the synchronization of high temperature and ample precipitation, which was the main feature of the temperate monsoon climate in Shandong Peninsula.

\subsection{The Relationship between Climate Change and the Monsoon Evolution}

It was generally recognized that global warming was primarily related to the greenhouse effect [2]. Therefore, the climate change in Shandong Peninsula was affected by the global warming inevitably. Besides, the atmospheric circulation is an important way for heat exchange and water vapor transport, and thus is the main factor for the formation of various climate conditions [36]. For the East 
Table 5. Monotonic trend tests for the percentage of June-September precipitation in the year at 18 hydrological stations in Shandong Peninsula.

\begin{tabular}{ccccccccc}
\hline Station & Period & $Z c$ & Percent & Station & Period & $Z c$ & Percent & $H_{o}$ \\
\hline JQ & $1965-2009$ & -0.85 & $69.84 \%$ & SWP & $1953-2009$ & -1.18 & $74.18 \%$ & $\mathrm{~A}$ \\
CLGJ & $1960-2009$ & -0.74 & $70.88 \%$ & JX & $1960-2009$ & -1.72 & $73.40 \%$ & $\mathrm{~A}$ \\
WW & $1959-2009$ & -1.54 & $71.70 \%$ & TK & $1952-2009$ & -1.09 & $72.62 \%$ & $\mathrm{~A}$ \\
SK & $1958-2009$ & -0.81 & $72.23 \%$ & MH & $1960-2009$ & -0.6 & $70.18 \%$ & $\mathrm{~A}$ \\
GL & $1952-2009$ & -0.93 & $74.61 \%$ & ZJZ & $1960-2009$ & -0.97 & $70.82 \%$ & $\mathrm{~A}$ \\
MYSK & $1959-2009$ & -0.75 & $73.40 \%$ & FS & $1966-2009$ & -0.35 & $67.19 \%$ & $\mathrm{~A}$ \\
LY & $1956-2009$ & -0.81 & $72.24 \%$ & ML & $1960-2009$ & -1.22 & $69.16 \%$ & $\mathrm{~A}$ \\
TW & $1957-2009$ & -0.31 & $71.95 \%$ & TC & $1952-2009$ & -1.02 & $74.02 \%$ & $\mathrm{~A}$ \\
WD & $1952-2009$ & -0.23 & $74.30 \%$ & QX & $1960-2009$ & -0.77 & $72.06 \%$ & $\mathrm{~A}$ \\
\hline
\end{tabular}

Asia monsoon climate in Shandong Peninsula, it was closely related to the interaction between winter monsoon and summer monsoon [14]. Many studies have found that the Siberia-Mongolia high was an important factor for temperature change in the East Asian monsoon area. The $1030 \mathrm{hPa}$ isobar southward expansion of Siberian high and the $500 \mathrm{hPa}$ geopotential height of SiberiaMongolian Plateau both experienced an abrupt change in mid-1980s [37,38], which was basically consistent with the transition point of temperature in Shandong Peninsula during the last 50 years. Since it can be inferred that the temperature change in Shandong Peninsula over the past 50 years may be highly impacted by the abrupt change of Siberia-Mongolia winter monsoon.

Precipitation in the East Asian monsoon region was directly related to the summer monsoon [29,39-45]. The maritime air masses associated with the summer monsoon brings about $75 \%$ of the annual precipitation in Eastern China [46]. Many research has shown that the East Asian summer monsoon suddenly weakened in late 1970s during the last 50 years, which might be related to the changes of the snow cover conditions in the Tibetan Plateau and the sea surface temperature in east central tropical Pacific [41-43,47]. Correspondingly, the precipitation in Northeastern China reduced significantly in late 1970 s, resulted by the sudden weaken of the summer monsoon $[30,35,43,44,48]$. The precipitation reduction in Shandong Peninsula was in the same period, therefore, we can speculate that the decrease of precipitation in Shandong Peninsula may be attributed to the changes in East Asian summer monsoon.

There are great difficulties to analyze the driving mechanism of climate change under the continental scale. The causal factors for climate change are diverse and complicated. It is hard to identify the impact of natural and anthoropogenic factors due to the local circulation and topographic complexity on a small scale [49]. This article is only a preliminary study for the main reason of climate change in the large-scale area where Shandong
Peninsula located, the rgional reason for the climate change in Shandong Peninsula requires further research.

\subsection{Spatial Difference of Climate Change in Shandong Peninsula}

As the barrier effect of the nearly east-west watershed located in central Peninsula, the northwestern Peninsula was more influenced by winter monsoon, while the summer monsoon was more significant in the southeast. Consequently, it presented distinct spatial variations of climate change within Shandong Peninsula. As described above, the reduction of precipitation was larger in the southeast while the increase of temperature was more significant in the northwest; meanwhile, the stations with earlier transition points of precipitation and temperature were located mostly in the southeastern Peninsula. This implied that the summer monsoon had an earlier change than winter monsoon. And we can further speculate that the impact of the Pacific Ocean on the monsoon climate in the study area was possibly greater than the Eurasia.

In conclusion, the coastal climate of Shandong Peninsula was characterised by a remarkable warming trend, which was on the basis of getting drier over the past 50 years. This variation in climate, coupled with the increase of the exploitation of water resources, will inevitably reduce the river runoff and sediment load into the coastal area [50-53]. Correspondingly, it will exert farreaching effects on the hydrological regime and sediment dynamic conditions of the bay and estuary: this will be the focus of further research.

\section{Conclusions}

The variation characteristics of both precipitation and temperature in Shandong Peninsula of China over the past 50 years have been studied in this paper. The major conclusions are:

1) The annual mean temperature of Shandong Peninsula showed a significant increasing trend and a distinct 
abrupt change was detected around 1990 during the past 5 decades. The change characteristics observed in annual minimum temperature was basically consistent with the annual mean temperature throughout the study area, except the Haiyang Station, which has an earlier transition point at 1972 . The annual maximum temperature exhibited a very complex change trend. Some stations showed a slight upward trend for the annual maximum temperature, while the opposite trend was observed in the other stations, but they were all statistically insignificant and no abrupt change was observed. Therefore, the direct cause that leads to the warming of Shandong Peninsula for the last 50 years was the significant increase of the annual minimum temperature.

2) The variation characteristics of precipitation, from June to September, seem to be in good agreement with the annual precipitation in Jiaodong Peninsula over the past 50 years. They showed a decreasing trend conformably, but the decreasing trend was significant at a few stations. The transition points of annual precipitation and June-September precipitation at most stations were detected around 1980, while a few stations showed an earlier transition point at 1966 . The reduction in the JuneSeptember precipitation was responsible mainly for the decrease of annual precipitation. Meanwhile, the proportion of June-September rainfall of the whole year declined slightly, but it was not significant.

3) The temperature increasing collocated with precipitation decreasing in Shandong Peninsula over the past 50 years. However, the abrupt change of precipitation was delayed for about 10 years, after the temperature. The variation characteristics of temperature in Shandong Peninsula was basically consistent with most parts of China, with the exact transition point being almost synchronous, but warmed at a faster rate over the same period; and the decreasing trend of precipitation in Shandong Peninsula was most significant all over China. Within the Peninsula, the abrupt change of temperature and precipitation in the Southeast was earlier than that in the Northwest; besides, the reduction of precipitation was larger in the Southeast while the increase of temperature was more significant in the Northwest.

\section{Acknowledgements}

This study was jointly funded by National Natural Science Foundation of China (No. 41071011 and No. 41171158); Key Project of Chinese Ministry of Education (No. 210122); Key Project of Natural Science Foundation of Shandong Province, China (No. Z2008E03); Science and Technology Planning Project of Higher Education in Shandong Province, China (No. J09LE07); Scientific and Technological Project of Yantai, China (No. 2008323). The authors are grateful for the support.

\section{REFERENCES}

[1] C. Keltoum, N. Luc, D. Claudine, P. Nicolas, L. Bernard, M. Eric, S. Dallas and C. Yvan, "Analyses of Precipitation, Temperature and Evapotranspiration in a French Mediterranean Region in the Context of Climate Change," Comptes Rendus Geoscience, Vol. 342, No. 3, 2010, pp. 234-243. doi:10.1016/j.crte.2010.02.001

[2] Intergovernmental Panel on Climate Change (IPCC), "Summary for Policymakers, in Climate Change 2007: the Physical Science Basis," In: S. Solomon, et al., Eds., Contribution of Working Group I to the 4th Assessment Report of the Intergovernmental Panel on Climate Change, Cambridge University Press, Cambridge, 2007, pp. 1-13.

[3] M. V. Flavio, L. D. P. Susana and A. S. Marcelo, "Analysis of the Global Warming Dynamics from Temperature Time Series," Ecological Modelling, Vol. 221, No. 16, 2010, pp. 1964-1978.

doi:10.1016/j.ecolmodel.2010.05.001

[4] V. Ramanathan and Y. Feng, "Air Pollution, Greenhouse Gases and Climate Change: Global and Regional Perspectives," Atmospheric Environment, Vol. 43, No. 1, 2009, pp. 37-50. doi:10.1016/j.atmosenv.2008.09.063

[5] Meteorological Administration of China, "Climate and Environment in China," Meteorology Press, Beijing, 2006.

[6] E. Lioubimtseva and G. M. Henebry, "Climate and Environmental Change in Arid Central Asia: Impacts, Vulnerability, and Adaptations," Journal of Arid Environments, Vol. 73, No. 11, 2009, pp. 963-977. doi:10.1016/j.jaridenv.2009.04.022

[7] Y. X. Liu, X. Li, Q. Zhang, Y. F. Guo, G. Gao and J. P. Wang, "Simulation of Regional Temperature and Precipitation in the Past 50 Years and the Next 30 Years over China," Quaternary International, Vol. 212, No. 1, 2010, pp. 57-63. doi:10.1016/j.quaint.2009.01.007

[8] T. Malone, P. Di Giacomo and E. Gonçalves, "Climate Change, Sustainable Development and Coastal Ocean Information Needs," Procedia Environmental Sciences, Vol. 1, 2010, pp. 324-341. doi:10.1016/j.proenv.2010.09.021

[9] C. S. Biliana and K. Robert, "Integrated Coastal and Ocean Management: Concepts and Practices," Island Press, Washington DC, 1998.

[10] N. Isabelle, D. Mamadou, F. Serigne, G. Khadim and N. Pape, "Impacts of Climate Change on the Senegalese Coastal Zones: Examples of the Cap Vert Peninsula and Saloum Estuary," Global and Planetary Change, Vol. 72, No. 4, 2010, pp. 294-301. doi:10.1016/j.gloplacha.2010.01.005

[11] J. N. Robert and A. L. Jason, "Benefits of Mitigation of Climate Change for Coastal Areas," Global Environmental Change Part A, Vol. 14, No. 3, 2004, pp. 229. 244.

[12] W. Z. Cao and M. H. Wong, "Current Status of Coastal Zone Issues and Management in China: A Review," Environment International, Vol. 33, No. 7, 2007, pp. 985992. doi:10.1016/j.envint.2007.04.009

[13] Y. Z. Zhang and D. K. Zhu, "Coastal Zone-The Key Area to the Studies on Global Change," Marine Science Bulletin, Vol. 16, No. 3, 1997, pp. 69-80. 
[14] Q. J. Sun, Y. Z. Lin, Y. L. Wu, S. D. Li and R. X. Jin, "Geography of Shandong Province," China Education Press, Beijing, 1987, p. 97.

[15] M. Domros and G. B. Peng, "The Climate of China," Springer-Verlag, Berlin, 1988, p. 360. doi:10.1007/978-3-642-73333-8

[16] Shandong China, Office of Land and Resources Staff, "Shandong Land Resources Atlas," Shandong Cartographic Publishing House, Jinan, 2007, p. 13.

[17] Z. Li, F. L. Zheng, W. Z. Liu and C. F. Dennis, "Spatial Distribution and Temporal Trends of Extreme Temperature and Precipitation Events on the Loess Plateau of China during 1961-2007," Quaternary International, Vol. 226, No. 1-2, 2010, pp. 92-100. doi:10.1016/j.quaint.2010.03.003

[18] X. M. Hao, Y. N. Chen, C. C. Xu and W. H. Li, "Impacts of Climate Change and Human Activities on the Surface Runoff in the Tarim River Basin over the Last Fifty Years," Water Resour Manage, Vol. 22, 2008, pp. 11591171. doi:10.1007/s11269-007-9218-4

[19] K. H. Xu, D. M. John and H. Xu, "Temporal Trend of Precipitation and Runoff in Major Chinese Rivers since 1951," Journal of Hydrology, Vol. 73, No. 3-4, 2010, pp. 219-232.

[20] Z. T. Cong, J. J. Zhao, D. W. Yang and G. H. Ni, "Understanding the Hydrological Trends of River Basins in China," Journal of Hydrology, Vol. 388, No. 3-4, 2010, pp. 350-356. doi:10.1016/j.jhydrol.2010.05.013

[21] X. Y. Li, Y. Luo and L. X. Wang, "Study on the Disturbance of Human Activities on the Hydrological Process in Tarim River Watershed," Journal of Zhengzhou University (Engineering Science), Vol. 23, No. 4, 2003, pp. 9398.

[22] Y. H. Yin, S. H. Wu and G. Chen, "Regional Difference of Climate Trend and Abrupt Climate Change in China during 1961-2006," Journal of Natural Resources, Vol. 24, No. 12, 2009, pp. 2147-2157.

[23] H. Y. Tang and P. M. Zhai, "Contrast of Variations of Surface Air Temperatures in Eastern and Western China during 1951-2002," Chinese Journal of Geophysics, Vol. 48, No. 3, 2005, pp. 61-69.

[24] H. Y. Tang, P. M. Zhai and Z. Y. Wang, "On Change in Mean Maximum Temperature, Minimum Temperature and Diurnal Range in China during 1951-2002," Climatic and Environmental Research, Vol. 10, No. 4, 2005, pp. 728-735.

[25] A. G. Lu, S. C. Kang, D. Q. Pang and T. M. Wang, "Asynchronous Temperature Variation across China under the Background of Global Warming," Arid Land Geography, Vol. 32, No. 4, 2009, pp. 506-511.

[26] G. Y. Ren, J. Guo, M. Z. Xu, Z. Y. Chu, L. Zhang, X. K. Zou, Q. X. Li and X. N. Liu, "Climate Changes of China's Mainland over the Past Half Century," Acta Meteorologica Sinica, Vol. 63, No. 6, 2005, pp. 942-956.

[27] P. M. Zhai and X. H. Pan, "Change in Extreme Temperature and Precipitation over Northern China during the Second Half of the 20th Century," Acta Geographica Sinica, Vol. 58, 2003, pp. 1-10.
[28] Z. G. Ma, C. B. Fu, X. B. Ren and C. Yang, "Trend of Annual Extreme Temperature and Its Relationship to Regional Warming in Northern China," Acta Geographica Sinica, Vol. 58, 2003, pp. 11-20.

[29] N. Zhang, Z. B. Sun and G. Zeng, "Change of Extreme Temperatures in China during 1955-2005," Journal of Nanjing Institute of Meteorology, Vol. 30, No. 1, 2008, pp. 123-128.

[30] Y. H. Ding, Z. Y. Wang and Y. Sun, "Inter-Decadal Variation of the Summer Precipitation in East China and Its Association with Decreasing Asian Summer Monsoon. Part I: Observed Evidences," International Journal of Climatology, Vol. 28, No. 9, 2008, pp. 1139-1161. doi:10.1002/joc. 1615

[31] Y. N. Chen, C. C. Xu, X. M. Hao, W. H. Li, Y. P. Chen, C. G. Zhu and Z. X. Ye, "Fifty-Year Climate Change and Its Effect on Annual Runoff in the Tarim River Basin, China," Quaternary International, Vol. 208, No. 1-2, 2009, pp. 53-61. doi:10.1016/j.quaint.2008.11.011

[32] Y. F. Shi, Y. P. Shen and R. J. Hu, "Preliminary Study on Signal, Impact and Foreground of Climatic Shift from Warm-Dry to Warm-Humid in Northwest China," Journal of Glaciology and Geocryolog, Vol. 24, No. 3, 2002, pp. 219-226.

[33] P. M. Zhai, X. B. Zhang, H. Wan and X. H. Pan, “Trends in Total Precipitation and Frequency of Daily Precipitation Extremes over China," Journal of Climate, Vol. 18, No. 7, 2005, pp. 1096-1108. doi:10.1175/JCLI-3318.1

[34] S. Buda, G. Marco and J. Tong, "Spatial and Temporal Variation of Extreme Precipitation over the Yangtze River Basin," Quaternary International, Vol. 186, No. 1, 2008, pp. 22-31. doi:10.1016/j.quaint.2007.09.001

[35] Q. Zhang, C. Y. Xu, Z. Zhang, Y. D. Chen and C. L. Liu, "Spatial and Temporal Variability of Precipitation over China, 1951-2005," Theoretical and Applied Climatology, Vol. 95, No. 1-2, 2009, pp. 53-68. doi:10.1007/s00704-007-0375-4

[36] Z. G. Zhao and L. Xu, "Potential Impact on El Ni no Events on the Circulation and Climate Variation in China," Wea Climate, Vol. 1, 2002, pp. 109-118.

[37] W. H. Qian, H. N. Zhang and Y. F. Zhu, "Interannual and Interdecadal Variability of East Asian Acas and Their Impact on Temperature of China in Winter Season for the Last Century," Advances in Atmospheric Science, Vol. 18, No. 4, 2001, pp. 511-523. doi:10.1007/s00376-001-0041-1

[38] D. Y. Gong and C. H. Ho, "The Siberian High and Climate Change over Middle to High Latitude Asia," Earth and Theoretical and Applied Climatology, Vol. 72, No. 1-2, 2002, pp. 1-9. doi:10.1007/s007040200008

[39] D. E. Zhang, H. C. Li, T. L. Ku and L. H. Lu, "On Linking Climate to Chinese Dynastic Change: Spatial and Temporal Variations of Monsoonal Rain," Chinese Science Bulletin, Vol. 55, No. 1, 2010, pp. 77-83. doi:10.1007/s11434-009-0584-6

[40] Q. Y. Guo, J. N. Cai, X. M. Shao and W. Y. Sha, "Interdecadal Variability of East-Asian Summer Monsoon and Its Impact on the Climate of China," Acta Geographica 
Sinica, Vol. 4, 2003, pp. 569-576.

[41] Y. H. Ding, Y. Sun, Z. Y. Wang, Y. X. Zhu and Y. F. Song, "Inter-Decadal Variation of the Summer Precipitation in China and Its Association with Decreasing Asian Summer Monsoon. Part II: Possible Causes," International Journal of Climatology, Vol. 29, No. 13, 2009, pp. 1926-1944. doi:10.1002/joc. 1759

[42] F. L. Yang and K. M. Lau, "Trend and Variability of China Precipitation in Spring and Summer: Linkage to Sea-Surface Temperatures," International Journal of Climatology, Vol. 24, No. 13, 2004, pp. 1625-1644. doi:10.1002/joc. 1094

[43] F. Huang, H. Wang and P. Dai, "Spatial-Temporal Characters of the Monsoon-Ocean Coupled Mode over the South China Sea and Its Relation with Summer Precipitation of China," Periodical of Ocean University of China, Vol. 37, No. 3, 2007, pp. 351-356.

[44] H. J. Wang, "The Weakening of the Asian Monsoon Circulation after the End of the 1970's," Advances in Atmospheric Sciences, Vol. 18, No. 3, 2001, pp. 376-386.

[45] Y. H. Ding and Y. Y. Liu, "A Study of the Teleconnections in the Asian-Pacific Monsoon Region," Acta Meteorologica Sinica, Vol. 22, No. 4, 2008, pp. 404-418.

[46] L. Q. Liang, L. J. Li and Q. Liu, "Precipitation Variability in Northeast China from 1961 to 2008," Journal of Hydrology, Vol. 404, No. 1-2, 2011, pp. 67-76.

[47] Y. S. Zhang, T. Li and B. Wang, "Decadal Change of the Spring Snow Depth over the Tibetan Plateau: The Associated Circulation and Influence on the East Asian Summer Monsoon," Journal of Climate, Vol. 17, No. 14, 2004 , pp. $2780-2793$.
doi:10.1175/1520-0442(2004)017<2780:DCOTSS $>2.0 . C$ $\underline{\mathrm{O} ; 2}$

[48] N. J. Wan, H. C. Li, Z. Q. Liu, H. Y. Yang, D. X. Yuan and Y. H. Chen, "Spatial Variations of Monsoonal Rain in Eastern China: Instrumental, Historic and Speleothem Records," Journal of Asian Earth Sciences, Vol. 40, No. 6, 2011, pp. 1139-1150. doi:10.1016/j.jseaes.2010.10.003

[49] M. V. C. Leila, J. Charles and L. Brant, "Extreme Precipitation Events in Southeastern South America and Large-Scale Convective Patterns in the South Atlantic Convergence Zone," Journal of Climate, Vol. 15, No. 17, 2002, pp. 2377-2394. doi:10.1175/1520-0442(2002)015<2377:EPEISS $>2.0 . C O$ ;2

[50] B. Claudine, C. Diane, C. Isabelle and G. R. André, "Impact of Climate Change on the Hydrology of St. Lawrence Tributaries," Journal of Hydrology, Vol. 384, No. 1-2, 2010, pp. 65-83. doi:10.1016/j.jhydrol.2010.01.011

[51] T. Hans, "The Influence of Climate Change on Stream Flow in Danish Rivers," Journal of Hydrology, Vol. 333, No. 2-4, 2007, pp. 226-238. doi:10.1016/i.jhydrol.2006.08.012

[52] D. E. Walling and D. Fang, "Recent Trends in the Suspended Sediment Loads of the World's Rivers," Global and Planetary Change, Vol. 39, No. 2-3, 2003, pp. 111126. doi:10.1016/S0921-8181(03)00020-1

[53] Y. M. Zhu, X. X. Lu and Y. Zhou, "Sediment Flux Sensitivity to Climate Change: A Case Study in the Longchuanjiang Catchment of the Upper Yangtze River, China," Global and Planetary Change, Vol. 60, No. 3-4, 2008, pp. 429-442. doi:10.1016/j.gloplacha.2007.05.001 